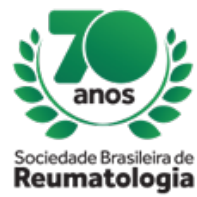

\title{
EMOTIONAL DISORDERS ASSOCIATED WITH RHEUMATOID ARTHRITIS
}

Maia Steffanie Vieira (Faculdade Santa Maria, Cajazeiras, PB, Brasil), Gleydson Oliveira da Silva (Faculdade Santa Maria, Cajazeiras, PB, Brasil), Claudia Sarmento Gadelha (Faculdade Santa Maria, Cajazeiras, PB, Brasil), Lillian Rodrigues Farias (Faculdade Santa Maria, Cajazeiras, PB, Brasil), Beatriz Torres Baltazar (Faculdade Santa Maria, Cajazeiras, PB, Brasil), Júlia Bezerra de Moraes (Faculdade Santa Maria, Cajazeiras, PB, Brasil), Heloysa Gonçalves de Araújo (Faculdade Santa Maria, Cajazeiras, PB, Brasil), Beatriz Brasileiro Diniz (Faculdade Santa Maria, Cajazeiras, PB, Brasil), Ana Luisa Gondim Pereira de Souza (Faculdade Santa Maria, Cajazeiras, PB, Brasil), Nargylla Bezerra de Lima (Faculdade Santa Maria, Cajazeiras, PB, Brasil)

\section{BACKGROUND}

Rheumatoid arthritis is characterized as a systemic and chronic autoimmune disease; however, it affects mainly the joints. As well as, it is incurable, but there were improvements in the treatment in the last years that corroborated with decreasing of the symptoms. Emotional factors such as anxiety, depression, and stress can be triggers to initiate Rheumatoid arthritis.

\section{MATERIALS AND METHODS}

This is a literature review based on the emotional disorders associated with rheumatoid arthritis, in which the descriptors registered in DeCS (Health Sciences Descriptors) were used: Anxiety AND Rheumatoid Arthritis AND Depression AND quality of life, published in the Pubmed and VHL (Virtual Health Library) databases, between 2014 and 2018.

\section{RESULTS}

Faced with the changes in the quality of life due to the functional disability resulting from rheumatoid arthritis, studies have found that patients with this disease have a higher incidence of anxiety and depressive disorders. Because it is a chronic inflammatory joint disease, rheumatoid arthritis is characterized by painful episodes and physical deformities, with consequent limitations in work and daily activities, which contributes to the sadness and demotivation. According to Sharpe et al., There is a close relationship between depression and the early stages of physical disability in patients with arthritis, and these have become more depressive with the evolution of the disease. Costa et al. and Mella et al. found that the prevalence of depressive symptoms in these patients is 33.7 and $53.2 \%$, respectively. Thus, the importance of the rheumatologist, in his evaluation and treatment proposal, to consider, besides the physical problems, the emotional issues and the impact on the quality of life that this disease can cause. Therefore, treatment of these conditions should include a good doctor-patient relationship, adequate orientation regarding the treatment of the disease, stimulation of physical activity, and, when necessary, the use of antidepressant and anxiolytic medications, in addition to the support of a psychologist or psychiatrist, sometimes.

\section{CONCLUSION}

Based on the results, we conclude that rheumatoid arthritis has a negative impact on the patient's life, including emotional disorders, since it is a very limiting disease, besides being painful. 